\title{
Psychiatric assessment in the emergency department: preliminary data from consumers about risk assessment following a suicide attempt or deliberate self-harm
}

\author{
Euan Donley
}

Correspondence: euan.donley@easternhealth.org.au

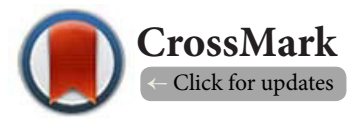

Emergency Department, Psychiatric Triage, Eastern Health and Monash University, Melbourne, Victoria, Australia.

\begin{abstract}
Suicide continues to be a world-wide problem. For every suicide there are many more suicide attempts and acts of deliberate self-harm. The Emergency Department (ED) of the public hospital is at the forefront of an increasing presentation rate of patients in the acute phase of mental illness or suicide risk, requiring specialised mental health risk assessment. Little is known of mental health patient views about their experience in the ED, yet consumer views are seen as an important factor in measuring the quality of psychiatric assessment and treatment. This paper sets out to examine consumer experiences of psychiatric assessment in the ED. Twenty participants, assessed in one of three public hospital EDs in Melbourne, Australia, following a suicide or deliberate self-harm (DSH) attempt, completed an anonymous online mixed method questionnaire. Participants reported an overall improvement in mood and expressed a positive view of the quality of service from the ED psychiatric team. Most helpful to participants was being listened to, not feeling judged, and having time to talk. What they found unhelpful was the lack of a private area for assessment, feeling 'labelled', and at times a lack of individual focus. What became apparent during this study was the difficulty in recruiting participants. A more direct-approach design to encouraging consumers to participate may increase response rates, however, privacy and power dynamics would pose an ethical challenge. Even though participation rate was low, the preliminary message from these ED consumers is still useful in formulating the beginnings of an important conversation with this group.
\end{abstract}

Keywords: Psychiatry, risk, emergency, assessment

\section{Literature review}

\section{Suicide and deliberate self-harm}

Suicide is a significant problem. The World Health Organisation [1] estimates world-wide there are about one million suicides per year. For every suicide there another ten to twenty suicide attempts $[\mathbf{2}, \mathbf{3}]$. The US Center for Disease Control reports there are approximately 100-200 attempts at suicide for every completed suicide [5]. The rate of suicide is likely to be higher as it is often considered a hidden problem in many countries [3] or investigators may record an open finding if there is no compelling evidence of a suicide. Suicide is the leading cause of premature mortality in the world [5] and a significant cause of death world-wide for 15-44 year olds [6].

Deliberate self-harm (DSH) is a problem for both the general and psychiatric community [7], is associated with increased risk of suicide at a later date $[\mathbf{8 , 9}]$ and is associated with significant mental health disorders [10]. It is estimated that about $4 \%$ of the population has deliberately self-harmed. This figure escalates to $7-9 \%$ for the adolescent population, and has been estimated at anywhere between $21-61 \%$ of people who have had a psychiatric inpatient admission [11]. In aged populations the occurrence of DSH is low; however, the rate of suicide following DSH is considerably higher [12]. The main reason for DSH in the older person is attributed to poor health, social isolation or mental illness [12].

Suicide risk, deliberate self-harm and the emergency department

The ED is at the forefront for an increasing presentation rate of people in the acute phase of a mental health problem or suicide risk $[13,14]$. The ED is well placed to treat cases of suicide risk and DSH as there are frontline medical staff to treat injuries, 
and usually mental health staff to provide assessments [2]. It is recommended that individuals presenting to an ED following DSH should receive mental health assessment before discharge [15].

"Mental health patients" will present to the ED in one of four contexts: covertly suicidal presenting with another problem; overtly suicidal brought to ED by themselves or others for help; patients who have just attempted suicide; and, patients declared dead upon arrival. Mental states can vary; for example some individuals are brought to the ED by police or family in an agitated state; others may be substance affected; some psychotic or delusional; while some may present in a highly distressed state. Thus the ED is often the first point of call for consumers requiring psychiatric assessment and treatment [4].

\section{Consumer perspectives of mental health assessment and treatment}

Over the last two decades people with mental illness have struggled to have their voice and experiences heard, thus minimising their capacity to influence the mental health system reform [16].

Yet, the consumer perspective is an important factor in developing and providing healthcare [17]. Consumer-lead research is an important tool in which to utilise the participant's own expertise about personal experiences with mental health services [18] and as a means of measuring the quality of care received [19]. Part of Australia's National Mental Health Strategy involves consumers having their say about mental health service delivery [19], and having consumer representatives employed in mental health services [20].

Mental health consumer surveys have generally found mixed results in terms of satisfaction with the treatment they receive. This can be influenced by the type of mental illness, the level of insight a consumer has, and whether the treatment was voluntary or otherwise.

Collaboration, feeling heard and shared decision-making have all been shown to be important to the mental health consumer [21]. Those who are informed about their illness and planning around treatment are likely to be more satisfied, which assists in better outcomes [22]. Age also plays an influence and older consumers generally have greater satisfaction with treatment. Consumers who were involuntary or psychotic were less satisfied, as were those with poor insight into their illness [23].

Consumers regularly report the need for basic courtesies such as having input into their care, feeling heard, involving family/carers, not feeling stigmatised, receiving timely care, and receiving holistic recovery-based care; these are integral to good practice from mental health services [24].

\section{Consumer perspectives of mental health treatment in the emergency department}

A number of themes impact mental health patient satisfaction when assessed in the ED. Feeling validated and having the time to talk with someone who could offer hope and a personalised plan for change is important. Not being judged, and believing the consumer's testimony about their circumstances are also factors associated with better satisfaction. For consumers who had previously received multiple assessments; asking the same questions, using the same strategies, or referring to the same services(s) was unhelpful, and could contribute to increased feelings of hopelessness [25].

There are barriers within the ED that can hamper therapeutic relationships when assessing the mental health consumer. Firstly, the ED is a loud and overcrowded area [26] with a very busy, urgent and high caseload. The ED assessment process is very risk-driven. There may be injuries to the consumer requiring urgent attention, or there may be a high risk to the mental health consumer or others requiring containment. This could mean constant one-on-one monitoring, restraint, or involuntary medical and psychiatric treatment [27]. The focus on this as a priority has the potential to impact on consumer satisfaction, especially if this is not the consumer's perspective of what is their priority or need. Sometimes the mental health consumer may not be well enough to understand explanations about their condition and management. This is of particular significance to EDs, as mental health consumers often present involuntarily, substance affected, mood disordered, or psychotic [28].

Given the ED sees so many mental health consumers in an atmosphere filled with potential barriers to the therapeutic relationship, there are surprisingly few studies exploring the ED mental health consumer perspective. Thus, a consumer-lead study of personal experiences of ED psychiatric assessment can assist in evaluating efficacy from a consumer viewpoint, and suggest how the balance of risk and service-delivery could be delivered in a consumer-friendly and recovery-based manner.

The role of psychiatric triage in the emergency department Eastern Health Psychiatric Triage in Melbourne and surrounds, Victoria, Australia provides a 24 hour, 7 day a week telephone and Hospital ED service. Eastern Health serves a population of 800,000 people, is one of Victoria's largest health networks, and has three hospital EDs. These EDs see over 140,000 patients each year and are a key point of contact with the health system for people with mental health problems (and their families/carers) who require urgent medical and/or psychiatric assessment and treatment. The purpose of a psychiatric assessment in the ED is to assess risk and current mental state, provide provisional diagnosis, and facilitate referral to either alternative mental health care or arrange admission to the hospital. Over the six month period of this study in the latter half of 2013, the ED Psychiatric triage service assessed 2,017 mental health patients with $63.3 \%$ being female.

\section{Aim and methods}

Aim

The aim of the study is to examine mental health consumer 
experiences of suicide risk assessment and management in the ED by psychiatric triage. The study asks specifically: to what extent are mental health consumers satisfied with psychiatric triage assessment and management in the ED?

\section{Definitions}

For this study, a suicide attempt is defined as self-injurious behaviour with a non-fatal outcome accompanied by evidence (explicit or implicit) that the person attempted to die [29]. Deliberate self-harm (DSH) is the wilful self-inflicting of destructive or injurious acts without intent to die [29]. A mental health consumer is an ED patient who has required specialist assessment from a psychiatric triage clinician following a suicide attempt, deliberate self-harm, or has suicidal ideation.

\section{Method}

Study participants who had attempted suicide or DSH were invited over a six-month period to participate in a 23 question online questionnaire. If they had been assessed in ED by psychiatric triage, they were recruited by a letter of invitation which was provided in person at the time of their discharge either from ED, CATT (the Crisis Assessment and Treatment Team supporting mental health patients in the community) or the mental health ward. Letters of invitation were also placed at three of the Eastern Health network's community mental health clinics' waiting rooms. Participants were assured of anonymity, that they could withdraw from the study at any time, and were advised who to contact if they required support as a result of undertaking the questionnaire. Persons under the age of 18 were excluded as they are not legally able to provide individual consent.

Ethics approval was granted by the health network (ref: LR25/ 1314) and Monash University (ref: CF13/2774-2013001494). Key stakeholders who needed to approve the study included the ED Directors, the psychiatric triage manager, the program director of adult mental health, the network chief psychiatrist, the manager of CATT and the inpatient ward nurse unit manager's.

The study employed a mixed methods approach to draw on both the strengths of qualitative and quantitative approaches and gather a range of data that increase the understanding of the research problem [30]. In this study mixed method analysis uses quantitative data to analyse trends, and qualitative data to allow open dialogue from participants. A thematic analysis of the qualitative data examined within the data and coded into themes [31].

\section{Study limitations}

The survey was completed in three public hospital EDs, while this gives some general reliability it is not representative of all EDs, private hospitals, or mental health wards. The questionnaire was fairly brief to increase engagement with participants. The response rate of twenty participants for over 2,000 presentations is very low making generalisation unrealistic. This low number is likely representative of staff at times having poor compliance with handing out the letter of invitation, and a population hesitant to participate in recalling what is likely to have been a distressing time.

On four occasions psych triage staff mentioned to this researcher they did not handout the letter of invitation when a consumer was particularly dis-satisfied with the outcome of the assessment. This trend has the potential to skew the data toward positive assessment experiences. This was an online survey, so those who completed the survey had access to the internet and require some degree of computer literacy. Their views may be different from those who could not access the survey.

\section{Findings \\ Participants}

Twenty participants with an age range of 18 to 55 years, of whom $70 \%$ were female and $30 \%$ male, completed the questionnaire. Participants reported they waited for a mental health assessment ranging from 0 to 2 hours (30\%), 2 to 4 hours (35\%) and 4 to 8 hours $(25 \%)$. It was the first assessment for $30 \%$ of participants. While $35 \%$ had received between one and 5 previous assessments, $15 \%$ had 5 to 10 previous assessments, and $20 \%$ reported previously having more than 10 assessments. The mode of arrival at the ED included $35 \%$ self-presentations, $20 \%$ of participants brought by a relative or friend, $10 \%$ arrived with police, $30 \%$ by ambulance, and $5 \%$ said they arrived by unidentified means.

\section{Relationship with worker}

Generally participants experienced the mental health clinician as caring with $55 \%$ saying the clinician cared a lot, $30 \%$ saying they cared a little, $15 \%$ saying they did not care much, and no participants reported the clinician did not care at all. Participants felt $70 \%$ of the time that their perspective and risk of harm was understood, with $20 \%$ reporting their risk was partly understood, and $10 \%$ reporting the mental health clinician did not understand their risk of harm at all. When asked if participants felt they were a part of the decision-making, $75 \%$ stated yes, and $25 \%$ stated no. Two participants (10\%) were treated involuntarily and both state they understood why, but report they were not made aware of their involuntary status rights.

Overall the interaction with the mental health clinician was rated as very good (55\%), good (20\%), average (20\%), poor (5\%), and none reported the overall interaction to be very poor. Participants were also generally happy with the ED nursing and medical staff with $25 \%$ reporting them as very good, $50 \%$ stating they were good, and $25 \%$ stating they were average. No respondents reported ED staff being poor or very poor. One participant wrote only one comment: "You saved my life" (MR1).

\section{Effect of risk assessment on self-reported mood}

Prior to assessment participants rated their mood out of ten. 
Zero being poor, and ten being good. The overall average was as $2.8 / 10$ pre-assessment, and 5.6/10 post-assessment. Participants were asked in an open format to explain to what they attributed the change in mood to $(\mathrm{N}=12$ : see Figure 1$)$.

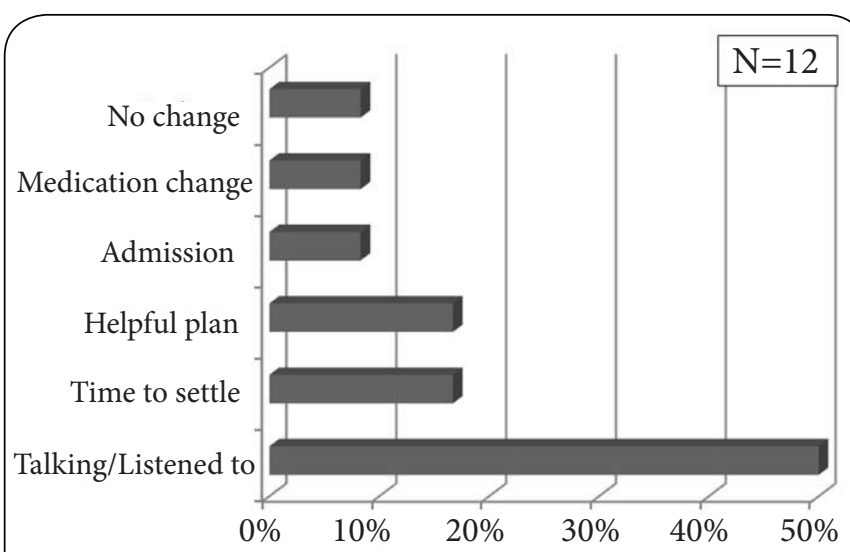

Figure 1. Attribution to change in mood.

Participants receiving their first assessment $(n=10)$ reported the biggest improvement in mood, from $2.5 / 10$ pre-assessment to $7 / 10$ post assessment. They also felt the clinician cared the most with $100 \%$ stating the clinician cared 'a lot' which was the highest option. Participants who had already experienced more than ten assessments $(n=4)$ had the least improvement in mood (from 4/10 to 4.25/10) and reported the clinician did not care ( $50 \%$ for both the clinician 'did not care much' and the clinician 'cared a little'). A higher proportion of these people felt labelled (25\%) and felt the mental health clinician had less empathy (50\%).

Participants who were brought in by police $(\mathrm{N}=2)$ generally waited less time, felt the clinician cared a lot, and felt their risk was understood. None were admitted to hospital and all reported feeling they were a part of the decision-making. The improvement in mood was slightly above the mean, ranging from 3 out of 10 , to 6.5 out of 10 after mental health risk assessment.

No participants reported their mood to be worse after risk assessment, while $5(20 \%)$ reported no change with an average mood rating as $2.4 / 10$. All the participants in this range were female aged between 18-55 with one stating: "There needs to be more supports out in the community. Despite all the promises over the years nothing has changed!!! (FR9)" The range of mood improvement before and after mental health risk assessment was similar between the sexes.

\section{Helpful aspects of assessment}

Some participants reported just having some time was helpful (16.7\%): "I had some time to settle down. And I must admit I was a little more sober when they spoke to me" (MR2). A further $16.7 \%$ reported having an appropriate plan was helpful. "The communication makes me feel more comfortable and they tried to help me out and solving my worries and respecting my preferences" (FR1). Other reasons attributed to change in mood were hospital admission (8.33\%) and medication change (8.33\%).

Talking to a mental health clinician was overwhelmingly a significant reason for an improvement in mood with $50 \%$ stating this was helpful."I had no idea what to do. The psychiatric worker sat with me for maybe an hour. They listened. I cried! I was worried I was having a breakdown or something, but they helped me feel a little more normal about what was going on." (FR2). While another reported: "It was nice to have some time to talk. I think the questions asked were really helpful and the guy helped me think I wasn't crazy. I also have some good friends that have been wonderful (FR3)."

Participants were openly asked to describe what they found helpful about the assessment after a suicide attempt or deliberate self-harm with $90 \%(\mathrm{~N}=18)$ making comments (see Figure 2). A thematic analysis noted overwhelmingly what was most helpful was categorised as time to talk and being listened to (61.1\%). "Just talking was great. Thank you." (FR4). "Time to talk was helpful. One of the nurses made me a cup of coffee. The guy (psychiatric triage clinician) helped me feel like I was not crazy" (MR3). "Being listened to" (FR2). Other participants commented on the value of the therapeutic relationship (22.2\%). "When I arrived there were a few police who brought me in. I

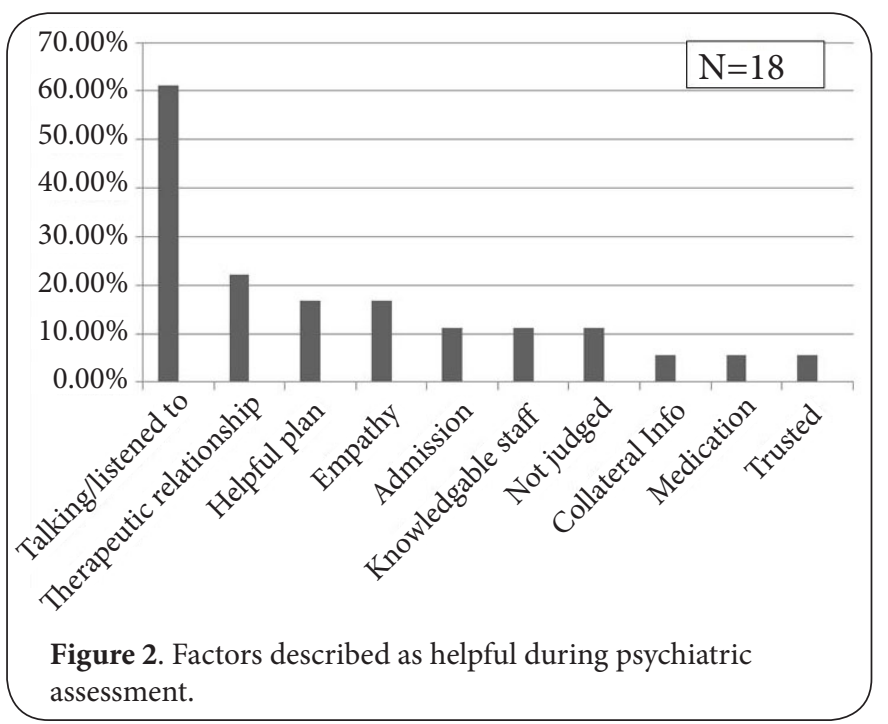

had (describes method of suicide attempt) and everybody was pretty serious. This guy came in and talked to me and within about three minutes we were talking about (sport)! I thought that this guy was really down to earth and easy to talk to. At the end he asked if I felt he understood where I was coming from". (MR3). Another study participant reported: "Thank you so very much for your help on that extremely dark day. You were completely professional, caring and understanding, and 
ensured that no harm would come to me of my own doing. At no stage did I feel lost, forgotten about, not cared for, or unsafe in any way" (MR4). One study participant who was assessed by two clinicians at interview highlighted the differences between good and unhelpful therapeutic relationships. "I saw two people that assessed me. The first one was a man and he was very helpful. He sat down with my husband and myself and talked for quite a while. I felt he cared what would happen. I had been drinking so he said he would get one of his colleagues to see me later. The second lady was quite abrupt to me, and I felt quite judged by her. She basically just told me to stop drinking. I am a (university) student and don't think her attitude was helpful. But overall I have been happy because the first man was so helpful." (FR5).

\section{Unhelpful aspects of risk assessment}

Study participants were asked to identify what was unhelpful about psychiatric assessment in ED after a suicide attempt or DSH (see Figure 3).

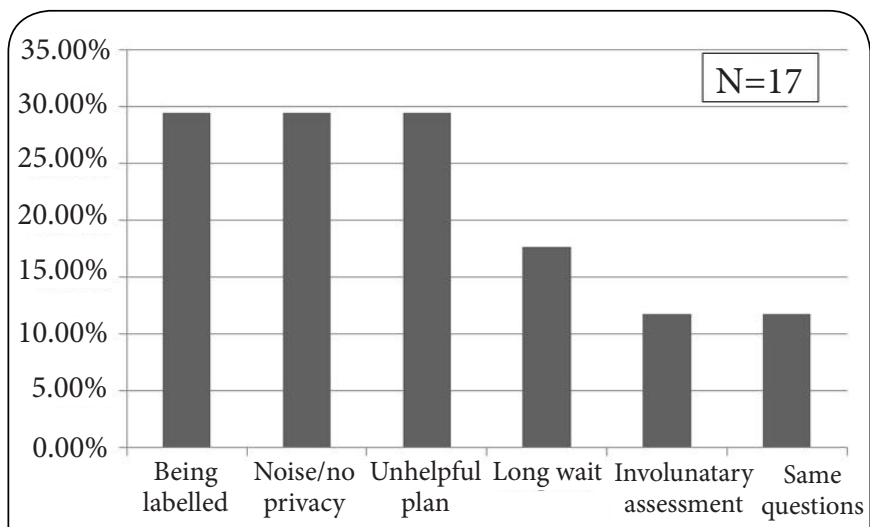

Figure 3. Factors described as unhelpful during psychiatric assessment in the ED.

A theme that was regularly mentioned was that consumers felt 'labelled' (29.4\%). One study participant reported: "Staff making assumptions based only on what they see/saw of me in the Emergency Department. Staff not being interested in the bigger picture. My normal abilities i.e., as a parent and an employee in the community rather than just assuming I was like that all the time" (FR5). With another stating: "I felt as though I was an unnecessary pest, and that I was just wasting their time" (FR8). This theme was consistent with another study participant who stated: "I think they believe I am attention seeking." (FR6).

Another consistent theme was the noise and lack of privacy in the ED (29.4\%). "The doctor and nurse spoke in front of my friends. But the psychiatric nurse asked if I wanted them present or to leave. It was also hard to hear at times and the psychiatric nurse was often asking me to repeat what I had just said. Which is embarrassing when you have to repeat you feel like killing yourself" (FR2). Another participant noted that privacy was an issue, but acknowledged the privacy difficulties were the created by the design of an ED: "The ED doctor spoke with me in the waiting room. I never really got into the emergency room. The mental health person saw me in a relative's office (a room set aside for relatives of people in $E D$, often used to interview patients when empty). The door was open but he did close it when people were walking by. I know you can't really do anything about that though" (MR2).

Other study participants reported that not having a relevant discharge plan was unhelpful (29.4\%), "Look. At the end of the day you can't really do anything. I come in and speak with someone. Sometimes I get admitted and other times I go home. But I look over my years (I have depression) and if I was to ask if I am better, I would have to say no. Every time all the psych team seem to think about is if I am going to kill myself or not. Or if I have been drinking. Are you supposed to be specialists? Anyone could ask that." (MR6).

A further factor considered unhelpful was involuntary treatment (11.8\%), "Having security in the room made me feel like I was a criminal. And I don't think it was nice to threaten me with involuntary treatment if I did not talk to you. I did not feel like talking. Also everyone could see me in that room" (FR7). The long wait to be seen was another unhelpful factor $(17.7 \%)$ as was being asked the same questions every time (11.8\%), "Nothing has ever changed in my life and each time the nurse comes in and asks me the same questions. Some people promise things and I never get them!!" (FR9).

\section{Open comments from participants}

The study participants were given the opportunity to offer suggestions as to what would improve the ED experience when receiving psychiatric risk assessment $(\mathrm{N}=17,85 \%$ of respondents). Ensuring an appropriate discharge plan was suggested by $29.41 \%$ of participants. A private area to talk was important (23.53\%). Participants also suggested staff do not label them (11.8\%), that waiting times should be improved $(11.8 \%)$, and staff should have more empathy (11.8\%). Obtaining corroborating information was also suggested (5.88\%) with one study participant stating: "When someone is seen by psych (Psychiatric Triage) in Emergency they may present completely different from their usual self. Triage staff should make the effort to contact family to ascertain that person's usual capabilities, so that they can make more informed decisions with or for that person. Many staff find mentally unwell people a nuisance and taking up too much time and if the staff knew that person's usual functioning they may treat the person differently" (FR5). Other study participants believed there should be more community supports (5.9\%) and better staff training (5.9\%).

Finally, study participants were given the opportunity to make general comments about the overall experience in ED ( $n=13,65 \%$ of respondents). Most $(46.1 \%)$ took the opportunity to thank the mental health service and ED, and some 
asked that thank you messages be passed on to the clinician: "Again, thanks to your skill along with (another staff member) at reception in ED, you have likely prevented either a full blown depression crash or death. I don't envy your job, it must be extremely demanding, but you performed it with great skill and care, and for that I am eternally grateful. Hopefully I never need your services again, but if I do, I know that I will be treated swiftly and properly, and that is very reassuring for someone who had such a low mood like myself, and has likely also helped to speed up my recovery" (MR3). Many who expressed that having pleasant staff was helpful (23.08\%), while others noted they hoped their comments would be of assistance to the study (15.4\%). Other themes included being listening to helped (7.7\%), there should be better staff training $(7.7 \%)$, collateral or family information should not be forgotten during an assessment (7.7\%), a reminder for staff not to label people (7.7\%), and re-iterating they did not find the assessment helpful (7.7\%).

\section{Discussion}

Overall, mental health consumers in this study found the ED risk assessment process a positive experience and it improved their mood. Still, the consumers who have attempted suicide or presented to ED report a number of factors that influence their experience of psychiatric risk assessment in the ED.

\section{Interpersonal/therapeutic factors}

The clinical and interpersonal skills of the psychiatric triage/ mental health or ED clinician will have a significant impact on the experience the consumer has with psychiatric risk assessment and outcomes.

Gilburt et al., [17] found patients in a psychiatric ward spoke more about the people they encountered, rather than the therapy(s) being provided. Themes such as trust and good communication were highly valued. Knowing more about the consumer as an individual and not just their diagnosis or presenting problem reduces the likelihood of a consumer feeling labelled or judged, as they feel they are being related to as a person [32]. Outcomes and compliance with management plans and treatment has been shown to improve if there is a good therapeutic relationship [33,34].

In ED there are factors that can hinder the therapeutic relationship. ED is a busy and often loud atmosphere with long waiting times, frequent interruptions and limited time [35]. Medical, nursing and allied health clinicians are dealing with multiple patients at any one time, and with limited time available. At times a consumer will present involuntarily in the presence of security or police, not in the mood to talk, and could be restrained. It is important that a skilled clinician can de-escalate difficult circumstances if they read the situation well and establish rapport in a quick amount of time where possible.

\section{Appropriate intervention plans}

A relevant plan comes from feeling heard, being actively involved in the risk assessment process, and can reflect not feeling judged or labelled.

A good intervention plan comes from a good assessment. A good recovery-based assessment should encompass: an empathic and respectful relationship; explore both the problems and strengths; use multiple sources for information; consider risk to the consumer or others; and, welcomes feedback. It is important to establish a respectful and empathic working relationship; identify the evidence base for the intervention or discharge plan; provide the consumer with information about the purpose, risks and nature of the intervention; the likely outcomes of the intervention; explores a range of alternative options; monitors other treating team members to ensure respectful decision-making; links family members into support where appropriate; negotiates time lines for the intervention; and, monitors the implementation and outcomes [36]. Monitoring and evaluation in the ED is unlikely due to the short-term nature of the department, so it may be useful to refer to another health professional. The role of the health professional would be to implement any specifics of the plan and review the plan, or adapt the plan if the risk changes, with the consumer.

\section{Environmental factors}

A private and quiet area to talk can be difficult within the ED environment. As noted, EDs are busy, loud, and often only thin curtains are the barrier between patients. This lack of privacy can have a negative impact on the therapeutic relationship, and could also discourage some consumers from talking at length. These factors obstruct comprehensive risk assessment, and may influence the outcome of an assessment. It would be recommended wherever appropriate and safe that a private area be used. Sadly, complete privacy is not always possible in $E D$, but sometimes reassuring a consumer any other patients in ED are generally focussed on their own health needs could alleviate any concerns. If this is not satisfactory, potentially apologising, and gently explain why the assessment is taking place in a populated area (such as the need to monitor for medical reasons).

Some hospitals utilise PAPUs (Psychiatric Assessment and Planning Units) attached to the ED. A PAPU is designed to provide a safe, but more private setting for further assessment and management. It is a unit attached to the ED, but designed specifically for mental health patients who require both monitoring and privacy. For example, the use of single rooms are more common, rather than ED cubicles and curtains. This type of unit would appear to address the privacy concerns participants reported, and not compromise safety of staff or consumers.

Participants did report that shorter waiting times would be helpful. However, the nature of ED is busy and people are seen on a triage basis. Shorter waiting is something most ED consumers would wish for, and not limited to the mental health community. Projects such as the mental health triage scale 
[37] have been helpful in prioritising mental health patients where those in the greatest distress or posing a high risk to themselves are prioritised treatment in ED. While National Emergency Access Targets (NEAT) are attempting to minimise access block to EDs [38]. For example, EDs are required to treat patients within 4-8 hours to prevent access block (long waiting times) and are able to utilise other hospital resources when required, meaning, in theory, the responsibility of care is not solely with ED.

Consumers also felt the presence of security or police was unhelpful. The safety of ED staff, mental health clinicians and surrounding patients is paramount, so at times this is unavoidable. If the consumer is appropriately orientated, this is an opportunity for the experienced clinician to highlight the seriousness of the presentation, and discuss how, together, security and police could be discharged. Where possible, it would also be useful for police and security to observe from a discrete area.

\section{The challenges of recruitment}

Recruiting participants for this study was a challenge. Partly due to the inconsistency of some staff to hand out letters of invitation to consumers, but this would only appear a small part of the picture. This study was designed to be as nonintrusive as possible, and allow the consumer to come to the study, rather than the reverse. The more a researcher is to push the consumer to participate, the more challenging this is from an ethical viewpoint. Potentially it can be more distressing to the participant, and it can create an uneven balance of power skewed to the researcher, especially if the consumer is hesitant in participating.

Interviewing participants immediately after an assessment is likely to be invasive, tiring (especially considering their ED presentation may be been very distressful), could escalate distress or agitation, and facilitates unreliable testimony. Therefore this study did not hand out invitation letters until point of discharge, to ensure potential participants had experienced the best opportunity for recovery. While having an anonymous online survey can reassure the participant that any negative feedback is not likely to be attributed to them.

This may be a good approach if a researcher has more than the six months available here to collate data. However, this avoidance to be obtrusive has meant that only preliminary data has been possible in this study. In the future it would be worth utilising an independent researcher, not directly attached to the health care network or psychiatric team. Their role would allow for follow up via a telephone-based interview if a consumer has given written consent at point of discharge. Prior consent would include appropriate contact details, any privacy wishes, and best times to interview. An experienced researcher could also identify any undue distress and respond appropriately if any risk issues arise.

Still, this study has been an important conversation starter between the Emergency Department and psychiatric con- sumers. If ED hopes to have a treatment alliance with this population, then the themes expressed in this study require further research with a significantly larger participation rate.

\section{Conclusion}

Suicide continues to be a significant challenge for the community and for mental health clinicians performing risk assessment in ED. The rate of presentations to ED increase each year placing pressure on all ED staff that treat them, often with limited training and resources. If EDs and consumers are to engage in a treatment alliance, and improve outcomes, then a joint discussion about experiences is essential. The data is here is preliminary and a conversation starter. This study highlighted improvement in mood following psychiatric assessment in ED when associated with a good therapeutic relationship. Of note the mental health consumer wants an opportunity to talk while not feeling judged or labelled. Areas for improvement in ED include the lack of privacy, insensitive use of security or police, and on occasion not experiencing a client-centred approach or suitable management plan. These findings reinforce the importance of the mental health consumer feeling an active part of the ED risk assessment process and treatment plan, which is in the spirit of recovery-focussed practice. Further research into consumer views is required if $E D$ recovery-based and consumer lead practice is to ever become more than lip service.

\section{Competing interests}

The author declares that he has no competing interests.

\section{Acknowledgement}

Author would like to thank Associate Professor Rosemary Sheehan, Monash University, Australia.

Publication history

EIC: Joseph Varon, University of Texas Medical Branch, USA.

Received: 15-Dec-2014 Final Revised: 29-Jan-2015

Accepted: 03-Feb-2015 Published: 12-Feb-2015

\section{References}

1. World Health Organization. The Global Burden of Disease: World Health Organisation: Geneva, Switzerland. 2008.

2. Olfson M, Marcus SC and Bridge JA. Emergency treatment of deliberate self-harm. Arch Gen Psychiatry. 2012; 69:80-8. | Article I PubMed

3. Kutcher $S$ and Chehil S. Suicide Risk Management: A Manual for Health Professionals. Blackwell Publishing. USA. 2009.

4. Ronquillo L, Minassian A, Vilke GM and Wilson MP. Literature-based recommendations for suicide assessment in the emergency department: a review. J Emerg Med. 2012; 43:836-42. | Article I PubMed

5. Thomas K, Chang SS and Gunnell D. Suicide epidemics: the impact of newly emerging methods on overall suicide rates - a time trends study. BMC Public Health. 2011; 11:314. | Article | PubMed Abstract | PubMed Full Text

6. Thomas K and Gunnell D. Suicide in England and Wales 1861-2007: a time-trends analysis. Int J Epidemiol. 2010; 39:1464-75. | Article | PubMed

7. Klonsky ED, Oltmanns TF and Turkheimer E. Deliberate self-harm in a nonclinical population: prevalence and psychological correlates. Am J Psychiatry. 2003; 160:1501-8. | Article | PubMed 
8. Sinclair JM, Hawton K and Gray A. Six year follow-up of a clinical sample of self-harm patients. J Affect Disord. 2010; 121:247-52. | Article | PubMed

9. Bradvik L, Mattisson C, Bogren $M$ and Nettelbladt P. Long-term suicide risk of depression in the Lundby cohort 1947-1997--severity and gender. Acta Psychiatr Scand. 2008; 117:185-91. | Article | PubMed

10. Beautrais AL, Joyce PR, Mulder RT, Fergusson DM, Deavoll BJ and Nightingale SK. Prevalence and comorbidity of mental disorders in persons making serious suicide attempts: a case-control study. Am J Psychiatry. 1996; 153:1009-14. | PubMed

11. de Klerk S, van Noorden MS, van Giezen AE, Spinhoven P, den HollanderGijsman ME, Giltay EJ, Speckens AE and Zitman FG. Prevalence and correlates of lifetime deliberate self-harm and suicidal ideation in naturalistic outpatients: the Leiden Routine Outcome Monitoring study. J Affect Disord. 2011; 133:257-64. | Article | PubMed

12. Barr W, Leitner $M$ and Thomas J. Do older people who self-harm receive the hospital care they need? Quality in Ageing and Older Adults. 2004; 5:10-19. | Article

13. Shafiei T, Gaynor $N$ and Farrell G. The characteristics, management and outcomes of people identified with mental health issues in an emergency department, Melbourne, Australia. J Psychiatr Ment Health Nurs. 2011; 18:9-16. | Article | PubMed

14. Hazlett SB, McCarthy ML, Londner MS and Onyike CU. Epidemiology of adult psychiatric visits to US emergency departments. Acad Emerg Med. 2004; 11:193-5. | Article | PubMed

15. National Institute for Clinical Practice (NICE). Self-harm: The short-term physical and psychological management and secondary prevention of self-harm in primary and secondary care. British Psychological Society and RC Psych Publications. 2004.

16. Anglicare Tasmania. Experts by Experience: Strengthening the mental health consumer voice in Tasmania. Tasmanian Mental Health Consumer Network. 2009. I Pdf

17. Gilburt $H$, Rose $D$ and Slade $M$. The importance of relationships in mental health care: a qualitative study of service users' experiences of psychiatric hospital admission in the UK. BMC Health Serv Res. 2008; 8:92. | Article | PubMed Abstract | PubMed Full Text

18. Bennetts W, Pinches A, Paluch T and Fossey E. Real Lives, real jobs: sustaining consumer perspective work in the mental health sector. Advances in Mental Health. 2013; 11:313. I Article

19. Stewart S, Watson S, Montague R and Stevenson C. Set up to fail? Consumer participation in the mental health service system. Australas Psychiatry. 2008; 16:348-53. | Article | PubMed

20. Tambuyzer $E$ and Van Audenhove C. Service user and family carer involvement in mental health care: divergent views. Community Ment Health J. 2013; 49:675-85. | Article | PubMed

21. Tanenbaum S. Psychiatrist-consumer relationships in US public mental health care: consumer's views of a disability system. Disability \& Society. 2009; 24:727-738| Article

22. Alexius B, Berg K and Aberg-Wistedt A. Patient satisfaction with the information provided at a psychiatric emergency unit. Patient Educ Couns. 2000; 40:51-7. I Article I PubMed

23. Ruggeri M, Lasalvia A, Bisoffi G, Thornicroft G, Vazquez-Barquero JL, Becker T, Knapp M, Knudsen HC, Schene A and Tansella M. Satisfaction with mental health services among people with schizophrenia in five European sites: results from the EPSILON Study. Schizophr Bull. 2003; 29:229-45. | Article | PubMed

24. Victorian Mental IIIness Awareness Council. What Consumers Want: Adversity to Advocacy. Mental Health Council of Australia. 2009. I Pdf

25. Hunter C, Chantler K, Kapur N and Cooper J. Service user perspectives on psychosocial assessment following self-harm and its impact on further help-seeking: a qualitative study. J Affect Disord. 2013; 145:315-23. I Article | PubMed

26. Randall JR, Colman I and Rowe BH. A systematic review of psychometric assessment of self-harm risk in the emergency department. J Affect Disord. 2011; 134:348-55. | Article | PubMed Abstract | PubMed Full Text

27. NSW Dept Health. Suicide Risk Assessment and Management: Emer- gency Department. New South Wales Department of Health: Sydney, Australia. 2005. I Pdf

28. Latt N, Jurd S, Tennant C, Lewis J, Macken L, Joseph A, Grochulski A and Long $L$. Alcohol and substance use by patients with psychosis presenting to an emergency department: changing patterns. Australas Psychiatry. 2011; 19:354-9. | Article | PubMed

29. Victorian Dept of Health. Working with the suicidal person: Clinical practice guidelines for emergency departments and mental health services. Dept of Health. 2010. I Pdf

30. Johnson R, Onwuegbuzie A and Turner L. Toward a Definition of Mixed Methods Research. Journal of Mixed Methods Research. 2007; 2:112133 | Article

31. Guest G. Applied thematic analysis. Thousand Oaks: California, Sage. 2012.

32. Shattell MM, Starr SS and Thomas SP. 'Take my hand, help me out': mental health service recipients' experience of the therapeutic relationship. Int J Ment Health Nurs. 2007; 16:274-84. | Article I PubMed

33. McCabe R, Bullenkamp J, Hansson L, Lauber C, Martinez-Leal R, Rossler W, Salize HJ, Svensson B, Torres-Gonzalez F, van den Brink R, Wiersma D and Priebe $S$. The therapeutic relationship and adherence to antipsychotic medication in schizophrenia. PLoS One. 2012; 7:e36080. | Article | PubMed Abstract | PubMed Full Text

34. Reininghaus U, McCabe R, Slade M, Burns T, Croudace T and Priebe S. The validity of patient- and clinician-rated measures of needs and the therapeutic relationship in psychosis: a pooled analysis. Psychiatry Res. 2013; 209:711-20. | Article | PubMed

35. Rhodes KV, Vieth T, He T, Miller A, Howes DS, Bailey O, Walter J, Frankel $\mathrm{R}$ and Levinson $\mathrm{W}$. Resuscitating the physician-patient relationship: emergency department communication in an academic medical center. Ann Emerg Med. 2004; 44:262-7. | Article | PubMed

36. Australian Association of Social Workers. Practice Standards for Mental Health Social Workers. AASW: Barton, Australia. 2008. I Pdf

37. Smart D, Pollard C and Walpole B. Mental health triage in emergency medicine. Aust N Z J Psychiatry. 1999; 33:57-66; discussion 67-9. | Article I PubMed

38. Mountain D. Introduction of a 4-hour rule in Western Australian emergency departments. Emerg Med Australas. 2010; 22:374-8. | Article | PubMed

Citation:
Donley E. Psychiatric assessment in the
emergency department: preliminary data from
consumers about risk assessment following a
suicide attempt or deliberate self-harm. Emerg
Med Health Care. 2015; 3:1.
http://dx.doi.org/10.7243/2052-6229-3-1

